\title{
Current trends among pediatric ophthalmologists to decrease myopia progression-an international perspective
}

Ofira Zloto ${ }^{1,2}$ \& Tamara Wygnanski-Jaffe ${ }^{1,2} \&$ Sonal K. Farzavandi ${ }^{3,4} \&$ Rosario Gomez-de-Liaño ${ }^{5}$ \& Derek T. Sprunger ${ }^{6} \&$ Eedy Mezer ${ }^{7,8}$

\begin{abstract}
Purpose To explore what the current worldwide preferred practice patterns of pediatric ophthalmologists are to decrease myopia progression among their patients.

Methods A questionnaire was sent to all members of supranational and national pediatric ophthalmology and strabismus societies.

Results The questionnaire was fully completed by most respondents $90.10 \%$ (847 of 940 responses). Fiftyseven percent (457) routinely treat to decrease myopia progression. The most common parameter to initiate treatment was a myopic increase of 1 diopter/year or more $(74.8 \%, 246)$. Seventy percent (345) prescribed eye drops. Atropine $0.01 \%$ was the most popular $(63.4 \%, 277)$ followed by atropine $1 \%(10.9 \%, 48)$ and atropine $0.5 \%(8.9 \%, 39)$. Eighty-six percent (394) of the respondents advised to spend more time outdoors, to reduce the amount of time viewing screens $(60.2 \%, 277)$, and cutback the use of smart phones $(63.9 \%, 294)$. Conclusions Most pediatric ophthalmologists treat to decrease myopia. They employ a wide variety of means to decrease myopia progression. Atropine $0.01 \%$ is the most popular and safe modality used similarly to recent reports. However, there is no consensus when treatment should be initiated. Further prospective studies are needed to elucidate the best timing to start treatment and the applicability of recent studies in the Asian population to other ethnic groups. This will improve the ability to update pediatric ophthalmologist with evidenced-based treatment options to counter the myopia epidemic.
\end{abstract}

Keywords: Myopia · IPOSC · Atropine - Behavioral treatment · Optical treatment

Ofira Zloto and Tamara Wygnanski-Jaffe share an equal contribution.

Electronic supplementary material The online version of this article contains supplementary material, which is available to authorized users.

* Eedy Mezer

emezer@gmail.com

1 Goldschleger Eye Institute, Sheba Medical Center, Ramat Gan, Israel

2 Sackler Faculty of Medicine, Tel Aviv University, Tel Aviv, Israel

3 Singapore National Eye Centre, Singapore, Singapore
4 Duke-National University of Singapore Graduate Medical School, Singapore, Singapore

5 Hospital Clínico/Instituto CastroviejoUniversidad Complutense Madrid, Madrid, Spain

6 Department of Ophthalmology, Pediatric and Strabismus Section, Indiana University School of Medicine, Indianapolis, IN, USA

7 Department of Ophthalmology, Ruth Rappaport Children's Hospital, Rambam Health Care campus, POB 9907, 3109901 Haifa, Israel

8 Bruce Rappaport Faculty of Medicine, Technion, Israel Institute of Technology, I.I.T, Haifa, Israel 


\section{Introduction}

Myopia is the most common visual disorder with increasing prevalence rates worldwide. Recent studies have shown that approximately $80 \%$ to $90 \%$ of Asian school children are my- opic [1-5]. In North America and in Europe, the prevalence of myopia has now increased to $40-60 \%$ in younger adults $[6,7]$. Holden et al. reported that myopia and high myopia will show a significant increase in prevalence globally, affecting nearly five billion people and one billion people, respectively, by 2050 . This would correspond to a 2.6-fold increase in the number of people with myopia from to 2010 to 2050 [8].

High myopia is a leading cause of irreversible visual impairment and can cause blindness even in children [9]. Myopia imposes heavy socioeconomic burdens on individuals and countries. Health economic studies reported that the medical cost of myopia far exceeded those of other major eye conditions such as retinal diseases and glaucoma $[10,11]$. 
The treatment to decrease the rate of myopia progression spans three modalities: pharmacological, optical, and behavioral. Each of these modalities includes numerous possibilities with different impact on myopia progression [12$16]$.

Nevertheless, there is no consensus to what is the best way to treat in order to prevent myopia progression, when to begin treatment, and in whom treatment should be tailored according to one's genetic background [17].

The purpose of the study was to explore the different interventions utilized by pediatric ophthalmologists worldwide to decrease the progression of myopia. This could map the current extent and type of involvement of this group of healthcare professionals to confront the epidemic of myopia affecting children and teenagers.

\section{Methods}

Survey population and questionnaire

An email communication was sent to all members of the International Pediatric Ophthalmology and Strabismus Council (IPOSC) and the American association for pediatric ophthalmology and strabismus (AAPOS) through IPOSC and AAPOS secretariat in December 2016. Responses were received until June 2017. The email included a web link to a survey (created on www.surveymonkey.com), explaining the purpose of the study, and offered a contact email and phone number that allowed the respondents to seek further clarification if needed. The questionnaire included 17 questions (Supplemental 1: English version; Supplemental 2: Spanish version). The required information included the characteristics of the myopic patients, personal preference of treatment, and the various interventions employed to slow the progression of myopia.

The questionnaire was also sent via the AAPOS
(1801 members) list server on three occasions and through the International Strabismological Association (ISA)-308 mem- bers, the AsiaPacific Strabismus and Paediatric Ophthalmology Society (APSPOS)-152 members, and various national societies secretariats to their members. This included countries in the Middle East, India (via the Society of Pediatric Ophthalmology and Strabismus of India, SPOSI), Far East Asia, and Latin America (via the Congress of the Latin American Council of Strabismus, CLADE). The total number of members from the different organizations cannot accurately be assessed because many respondents are members of more than one organization, for example, membership in a national as well as one or more supranational organizations. The questionnaire was translated from English to Spanish, and the introduction was translated to Chinese and Korean. 
For those in India whose email was not available, the sur- vey was sent as a message via the WhatsApp application (WhatsApp Inc., CA, USA).

All authors declared no financial or nonfinancial conflict of interest, and no formal consents were required as the information obtained through the questionnaire did not refer to a specific patient but rather to the general clinical treatment patterns of the respondent. The study adhered to the principles outlined in the Declaration of Helsinki and was approved by the local institutional review board (IRB) of Sheba Medical Center.

Statistical analysis

Statistical analysis, including distribution, was performed with the JMP Statistical Discovery Software 7.0 (SAS Institute, Cary, NC, USA). The overall significance level was set to an alpha of 0.05 .

\section{Results}

Nine hundred forty members of the various pediatric ophthalmology and strabismus organizations responded to the questionnaire. The survey was fully completed by $90.1 \%$ (847) of the respondents that had participated in the survey.

Almost one fifth of the responders (18.1\%, 163 of 899 who replied to this question) had practiced pediatric ophthalmology for less than 5 years, $15.7 \%$ (141) for 5 to 10 years, $16.79 \%$

(151) for 10 to 15 years, $14.1 \%$ (127) for 15 to 20 years, $13.2 \%$ (119) for 20 to 25 years, and $22.0 \%$ (198) for more than 25 years.

The place of employment was a multichoice question. Accordingly, 1005 choices were received from 940 respondents. Roughly a third $(37.5 \%, 377)$ of respondents work at a university-based hospital, 23.1\% (232) work at a multispecialty private group practice, $21.7 \%$ (218) in a hospital, and $17.7 \%$ (178) at a group practice.
Most responses came from North America (26.8\%, 227), Far East Asia $(16.6 \%, 141)$, and Europe $(16.3 \%, 138)$. The complete geographical distribution is depicted in Table 1.

The three countries with most replies were the USA $(21.3 \%, 200)$, India $(8.6 \%, 81)$, and Japan $(5.7 \%, 54)$. The distribution of all countries of residence of the respondents is summarized in Table 2.

Reports of more than one ethnic background of the patients in the survey were allowed. Therefore, 1764 choices were chosen by the 940 respondents: Caucasian descent $(26.1 \%, 460)$, Indian (23.7\%, 419), Far East Asian (20.1\%, 355), African (12.4\%, 219), Arab (11.2\%, 197), and Hispanic

$(6.5 \%, 114)$. 
Table 1Geographical distribution of 847 respondents

\begin{tabular}{ll}
\hline $\begin{array}{l}\text { Continent } \\
\text { respondents }\end{array}$ & $\begin{array}{l}\text { Percentage of } \\
\text { (numbers) }\end{array}$ \\
\hline North America & $26.8 \%(227)$ \\
Far East & $16.6 \%(141)$ \\
Europe & $16.2 \%(138)$ \\
Central Asia & $14.7 \%(125)$ \\
South America & $10.3 \%(87)$ \\
Middle East & $8.5 \%(72)$ \\
Central America & $2.4 \%(21)$ \\
Australia & $2.0 \%(17)$ \\
Africa & $1.9 \%(16)$ \\
New Zealand & $0.3 \%(3)$ \\
\hline
\end{tabular}

Treatment for decreasing myopia

The majority of pediatric ophthalmologists, who have participated in the current study, routinely treat to decrease the rate of myopia progression $(57.0 \%, 457$ out of 801 who have answered this question). An average of $57 \%$ of respondents advocated treatment to decrease the rate of myopia progression. This ranged considerably from $89 \%$ in Australia and New Zealand to $12 \%$ in Africa (Table 3).

Most of them have been treating patients for the past year

or two $(42.7 \%, 215$ out of 504 responses for this question),

$28.4 \%$ (142) have been treating patients for 3 to 5 years,

$12.4 \%(61)$ have been treating patients for 6 to 10 years, and

$16.4 \%$ (86) have been treating for more than 10 years.

When treatment should be initiated

The most common parameter in the current study to initiate treatment was when respondents documented an increase in myopia at an average rate of 1 diopter/year or more $(53.4 \%, 246$ out of 461 who have replied to this question). Twenty-one percent (96) initiated treatment as soon as they have identified myopia at an average age of 5.3 years of age (median 5, range

Table 2Country distribution

Country

respondents for
Percentage of

each country (numbers)
USA

India

Japan

Taiwan

Spain

Republic of Korea, Israel

Canada

Chile
$21.3 \%(200)$

$8.6 \%(81)$

$5.7 \%(54)$

$3.6 \%$ (34)

$3.5 \%$ (33)

$3.2 \%$ (30)

$2.6 \%(25)$

$2.2 \%(21)$ 
Argentina, Islamic Republic of Iran

$2.1 \%(20)$

Brazil

$1.9 \%(18)$

Australia, Mexico

$1.8 \%(17)$

China

$1.4 \%(13)$

$1.2 \%(11)$

Singapore

$1.1 \%(10)$

Azerbaijan, Italy, Turkey

$0.9 \%(9)$

Bangladesh, Britain

$0.8 \%(8)$

Belgium, Egypt, Portugal, Venezuela

$0.7 \%(7)$

Colombia, France, Nigeria, Peru, Romania, Russia

$0.6 \%(6)$

Denmark, Germany, Indonesia

$0.5 \%(5)$

Croatia, Greece, Saudi Arabia, Ukraine

$0.4 \%(4)$

Albania, Austria, Bolivia, Bulgaria,

$0.3 \%(3)$

Dominican Republic, Ecuador, Jordan, New

Zealand

$0.2 \%(2)$

El Salvador, Hong Kong, Hungary, Malaysia,

Netherlands, Serbia, Switzerland, Thailand,

$0.1 \%(1)$

Vietnam

Afghanistan, Angola, Argentine, Bahrain, Bharat, Dubai, Finland, Guatemala, Ireland, Lithuania, Macedonia, Myanmar, Nepal, Norway, Oman, Paraguay, Puerto Rico,

Qatar, South Africa, Sweden, Tunisia 
Table 3 How many pediatric ophthalmologists advocate treatment to decrease the rate of myopia progression in each geographical region

\begin{tabular}{|c|c|c|}
\hline Continent & $\begin{array}{l}\text { Treatment } \\
\text { recommende } \\
d^{*}\end{array}$ & $\begin{array}{l}\text { Treatment } \\
\text { not } \\
\text { recommen } \\
\text { ded* }^{*}\end{array}$ \\
\hline $\begin{array}{l}\text { Australia and New } \\
\text { Zealand }\end{array}$ & $88.9 \%(16)$ & $11.1 \%(2)$ \\
\hline Far East & $70.2 \%(99)$ & $\begin{array}{l}29.8 \% \\
(42)\end{array}$ \\
\hline North America & $63.8 \%(143)$ & $\begin{array}{l}36.2 \% \\
(81)\end{array}$ \\
\hline Central America & $57.1 \%(12)$ & $42.8 \%(9)$ \\
\hline All respondents & $57.0 \%(457)$ & $\begin{array}{l}42.9 \% \\
(344)\end{array}$ \\
\hline Central Asia & $56.5 \%(65)$ & $\begin{array}{l}43.5 \% \\
(50)\end{array}$ \\
\hline South America & $54.8 \%(46)$ & $\begin{array}{l}45.2 \% \\
(38)\end{array}$ \\
\hline Middle East & $41.3 \%(31)$ & $\begin{array}{l}58.7 \% \\
(44)\end{array}$ \\
\hline Europe & $38.3 \%(44)$ & $\begin{array}{l}61.7 \% \\
(71)\end{array}$ \\
\hline Africa & $12.5 \%(1)$ & $87.5 \%(7)$ \\
\hline
\end{tabular}

*Percentage (number) of respondents

2 to 8 ). Fourteen percent (62) initiated treatment as soon as they have identified myopia above 3.5 diopters.

Most respondents $(51.0 \%, 242$ out of 474 responses to the question) did not know at what age response to treatment was most effective to decrease the rate of myopia progression. The average reported age to treat most effectively was 9.71 years old (median 9.75, range 1 to 35). Figure 1 summarizes all the responses to this query.

Treatment modalities

The most effective modality was thought to be pharmacological treatment $(54 \%, 266$ out of 493 replies to the question), followed by behavioral treatment $(24.7 \%, 122)$ and optical treatment
$(21.3 \%, 105)$.

Pharmacological treatment

Most ( $70 \%, 345$ out of 493 who have responded to this question) prescribed eye drops in order to slow the progression of myopia. The average age eye drops were initiated was 5.23 (median was 5, range 0.5 to 16 years old). More than one option was allowed, which resulted in 439 answers from 345 respondents to this question. The most popular medication was atropine $0.01 \%(63.5 \%, 279)$, atropine $1 \%(10.9 \%, 48)$,

and atropine $0.5 \%(8.9 \%, 39)$. Figure 2 summarizes the distribution of all the pharmacological agents.

Atropine $0.01 \%$ was the pharmacological treatment with the highest number of respondents that have not discontinued treatment in any of their patients receiving these eye drops $(63.8 \%, 178)$. A few patients reported a rebound effect after discounting the use of atropine $0.05 \%$ (66.7\% had no rebound effect). In contrast, all patients that applied pirenzepine, homatropine, and atropine $0.3 \%$ suffered from a rebound effect upon cessation of this medication. The complete list of 
typical eye drops utilized by the respondents is displayed in Table 4.

\section{Optical correction}

The type of optical correction was a multichoice question. Therefore, 791 answers were received from 393 responses to this question. Thirty-four percent (268) of the respondents prescribed fullcorrection spectacles, followed by spectacle with progressive addition lenses $(11.6 \%, 92)$, and orthokeratology $(10.5 \%, 83)$. Those and other types of optical correction are summarized in Fig. 3.

\section{Behavioral recommendation}

The type of behavioral recommendation was also a multichoice question. Therefore, 1396 answers were received from 439 ophthalmologists. Most respondents recommended to spend more time outdoors $(27.9 \%, 390)$, to lessen the usage of smartphones $(20.8 \%, 290)$, and to watch monitor screens and the television less frequently $(19.6 \%$, 274). All the recommendations are delineated in Fig. 4.

\section{Discussion}

Myopia is one of the most common ocular disorders in the world [6, 18] with a different incidence worldwide [16, 19]. This worldwide survey summarizes the various approaches of pediatric ophthalmologists to treatment to decrease myopia progression.

Nine hundred forty pediatric ophthalmologists participated in the survey. Most of them were seasoned professionals with over 10 years of experience in pediatric ophthalmology. Not surprisingly, almost $60 \%$ of respondents worked at a hospital mostly academically affiliated, thus perhaps increasing the number of early adaptors of new ways to treat including to decrease myopia progression.

There was a large representation from North America, Far East, Europe, and central Asia with the smallest number of reports from Australia,
New Zealand, and Africa. This is mainly due to the lower number of doctors practicing medicine in these regions either because of a smaller population in Australia or due to a scarcity of medical doctors in Africa $[20,21]$.

The ethnic diversity of patients treated by the respondents covered mostly those of Caucasian, Indian, or Far East Asian descent, due to the geographical locations of the respondents. China was specifically underrepresented with only 13 ophthalmologists due perhaps to language as well as other barriers preventing this survey from reaching a significant number of potential respondents. Nevertheless, this is the first survey to include multi-international centers around the world. 
Fig. 1 The age at which the respondents deemed the treatment to decrease myopia to be most effective

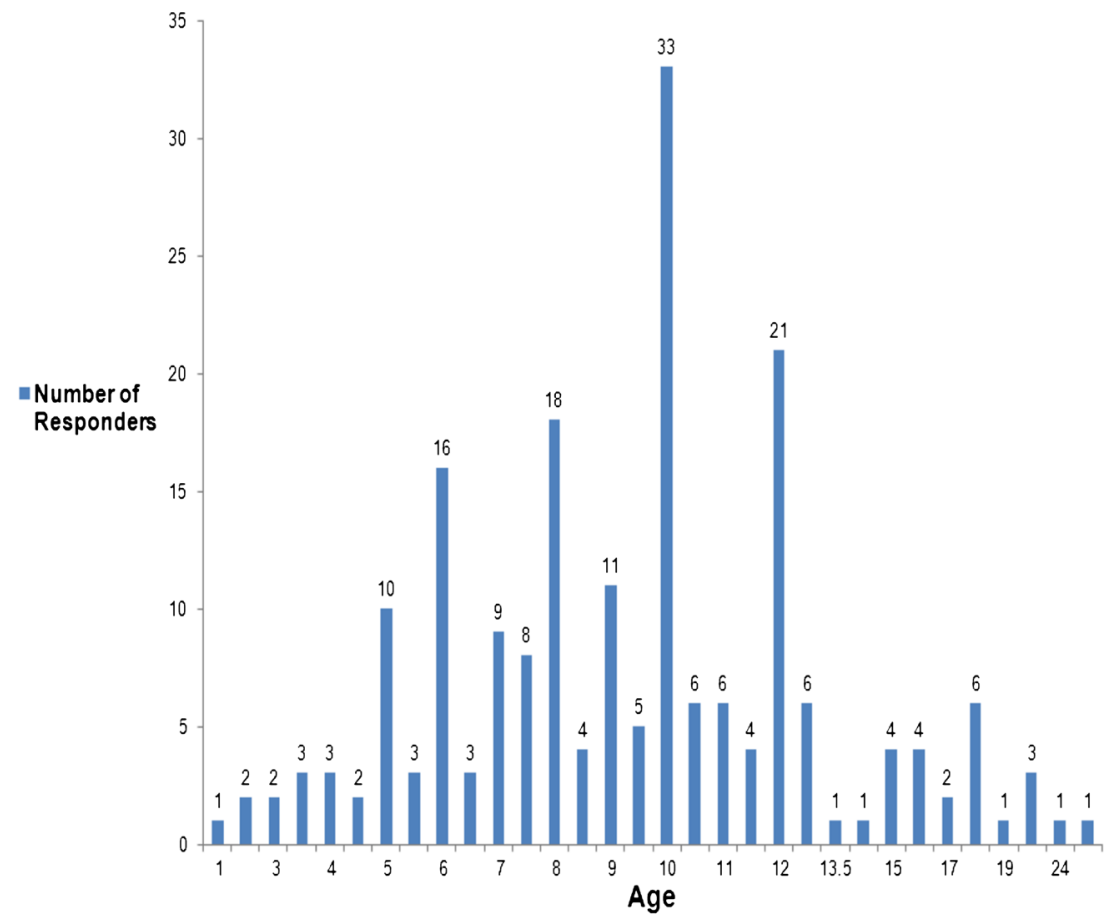

Treatment of myopia at an early stage before it increases to high myopia can significantly reduce the risk of retinal detachment, glaucoma, cataract, and macular degeneration. All these conditions are much more prevalent in high my- opia and can lead to blindness [9]. Therefore, it was disconcerting to find out that about $43 \%$ of the respondents in the current survey do not routinely treat to decrease myo- pia. More specifically, almost $90 \%$ of the respondents in Africa, and around $60 \%$ in Europe and Middle East, do not treat routinely to decrease myopia. People of African descent are known to have has less myopia 5-7\% in aver- age $[8,22]$ as well as residents of the Middle East of Arab descent (1.45\% in rural areas and $3.16 \%$ in urban area) [22]. Therefore, preventing myopia in those regions does not cause as much concern as in Far East Asia where the prevalence of myopia in 2010 was $47 \%$ and is predicted to be $65.3 \%$ in 2050 [8]. Li et al. found already that the prevalence rates of myopia in central China are 67.3\% in grade 7 [23]. There have recently been some epidemiological reports from Europe about an increase in the incidence of 


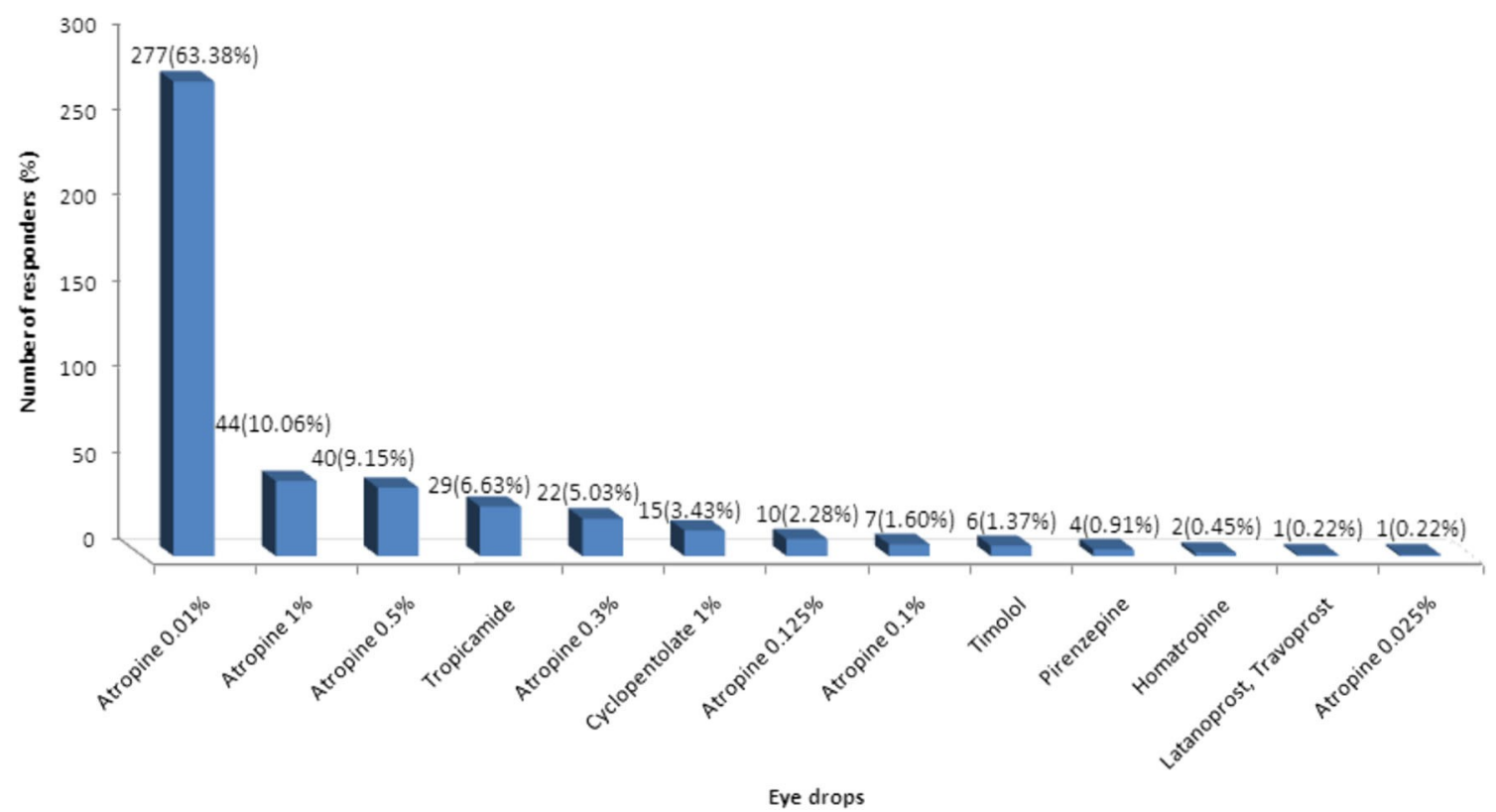

Fig. 2 Topical medications used to decrease myopia progression 
Table 4Rebound effect of eye drops prescribed by pediatric ophthalmologists to decrease the progression of myopia

\begin{tabular}{|c|c|c|c|c|}
\hline Eye drops & $\begin{array}{l}\text { Respondents that } \\
\text { have not } \\
\text { discontinued } \\
\text { treatment in any of } \\
\text { their patients }\end{array}$ & $\begin{array}{l}\text { Respondents whose } \\
\text { patients have } \\
\text { discontinued treatment } \\
\text { Rebound effect } \\
\text { experienced after } \\
\text { discontinuing eye } \\
\text { drops* }\end{array}$ & $\begin{array}{l}\text { No rebound effect } \\
\text { after } \\
\text { discontinuing eye } \\
\text { drops* }\end{array}$ & $\begin{array}{l}\text { Total number of } \\
\text { respondents whose } \\
\text { patients received } \\
\text { treatment }\end{array}$ \\
\hline $\begin{array}{l}\text { Latanopr } \\
\text { ost, } \\
\text { travopr } \\
\text { ost }\end{array}$ & $\begin{array}{l}100 \%(1) \\
63.8 \%(178)\end{array}$ & $36.2 \%(101)$ & & 279 \\
\hline $\begin{array}{c}\text { Atropine } \\
\text { U.U1\% }\end{array}$ & & $52.5 \%(53)$ & $47.5 \%(48)$ & \\
\hline Timolol & $60 \%(3)$ & $\begin{array}{l}40 \%(2) \\
0 \%(0)\end{array}$ & $100 \%(2)$ & 5 \\
\hline $\begin{array}{l}\text { Pirenzepin } \\
\mathrm{e}\end{array}$ & $33.3 \%(1)$ & $\begin{array}{l}66.7 \%(2) \\
100 \%(2)\end{array}$ & $0 \%(0)$ & $\begin{array}{l}3 \\
0 \%(0)\end{array}$ \\
\hline $\begin{array}{l}\text { Atropine } \\
1 \%\end{array}$ & $25 \%(12)$ & $\begin{array}{l}75 \%(36) \\
50 \%(18)\end{array}$ & $50 \%(18)$ & 48 \\
\hline $\begin{array}{l}\text { Tropicami } \\
\text { de }\end{array}$ & $25 \%(7)$ & $\begin{array}{l}75 \%(21) \\
42.9 \%(9)\end{array}$ & $57.1 \%(12)$ & 28 \\
\hline $\begin{array}{l}\text { Atropine } \\
0.5 \%\end{array}$ & $20.5 \%(8)$ & $\begin{array}{l}79.5 \%(31) \\
74.2 \%(23)\end{array}$ & $25.8 \%(8)$ & 39 \\
\hline $\begin{array}{l}\text { Atropine } \\
0.1 \%\end{array}$ & $18.7 \%(3)$ & $\begin{array}{l}81.3 \%(13) \\
69.2 \%(9)\end{array}$ & $30.8 \%(4)$ & 16 \\
\hline $\begin{array}{l}\text { Cyclopent } \\
\text { olate } \\
1 \%\end{array}$ & $14.3 \%(2)$ & $85.7 \%(12)$ & $41.7 \%(5)$ & 14 \\
\hline $\begin{array}{l}\text { Atropine } \\
0.3 \%\end{array}$ & $0 \%(0)$ & $\begin{array}{l}100 \%(2) \\
100 \%(2)\end{array}$ & $0 \%(0)$ & 2 \\
\hline Atropine & $0 \%(0)$ & $\begin{array}{l}100 \%(3) \\
33.3 \%(1)\end{array}$ & $66.7 \%(2)$ & 3 \\
\hline $\begin{array}{l}\text { Homatropi } \\
\text { ne }\end{array}$ & $0 \%(0)$ & $\begin{array}{l}100 \%(1) \\
100 \%(1)\end{array}$ & $0 \%(0)$ & 1 \\
\hline Total & $49 \%(215)$ & $51 \%(224)$ & & 439 \\
\hline
\end{tabular}


$*(\%)$, percentage out of total number of respondents, whose patients have discontinued eyes' drops

myopia and high myopia from 17.8 to $23.5 \%$ in those born between 1910 and 1939 compared with 1940 and 1979 and predicted to increase from $28.5 \%$ in 2010 to $56.2 \%$ in $2050[8,24]$. However, it seems that pediatric ophthalmologists in Europe have yet to increase their active participation to face the challenge of the myopia epidemic.

This study shows that treatment to decrease myopia progression has picked up in recent years as more pediatric ophthalmologists started to get involved and provide this service. This may be related to the increase in publications on this topic. A MEDLINE database search utilizing myopia as a keyword yielded 203 articles published during 2007, 242 papers released during 2012, and 306 studies

during 2017.

In the current survey, more than half of the respondents opted to initiate treatment when myopia increased more than $1 \mathrm{D} /$ year. This is in accordance with some of the published literature [25] while others started when myopia progression of $-0.50 \mathrm{D} /$ year or more [26].

There is no consensus in the literature when to start treating to decrease myopia $[25,27,28]$. Similarly, most of the respondents in this survey did not know at what the age the response to treatment was most effective. In most of the study, the average was 6 to 12 years old [24, 26, 27] which is in accordance with the average age that was found in this study (10 years old).

Currently, there are no accepted guidelines what is the best medication suited to lessen myopia progression. In 2011, the Cochrane Database examined the published evidences of the progression of nearsightedness in myopic children. They examined eye drops such as atropine and pirenzepine versus under correction of nearsightedness versus multifocal spectacles and contact lenses. They concluded that the most likely effective treatment to slow myopia progression thus far is anti- 


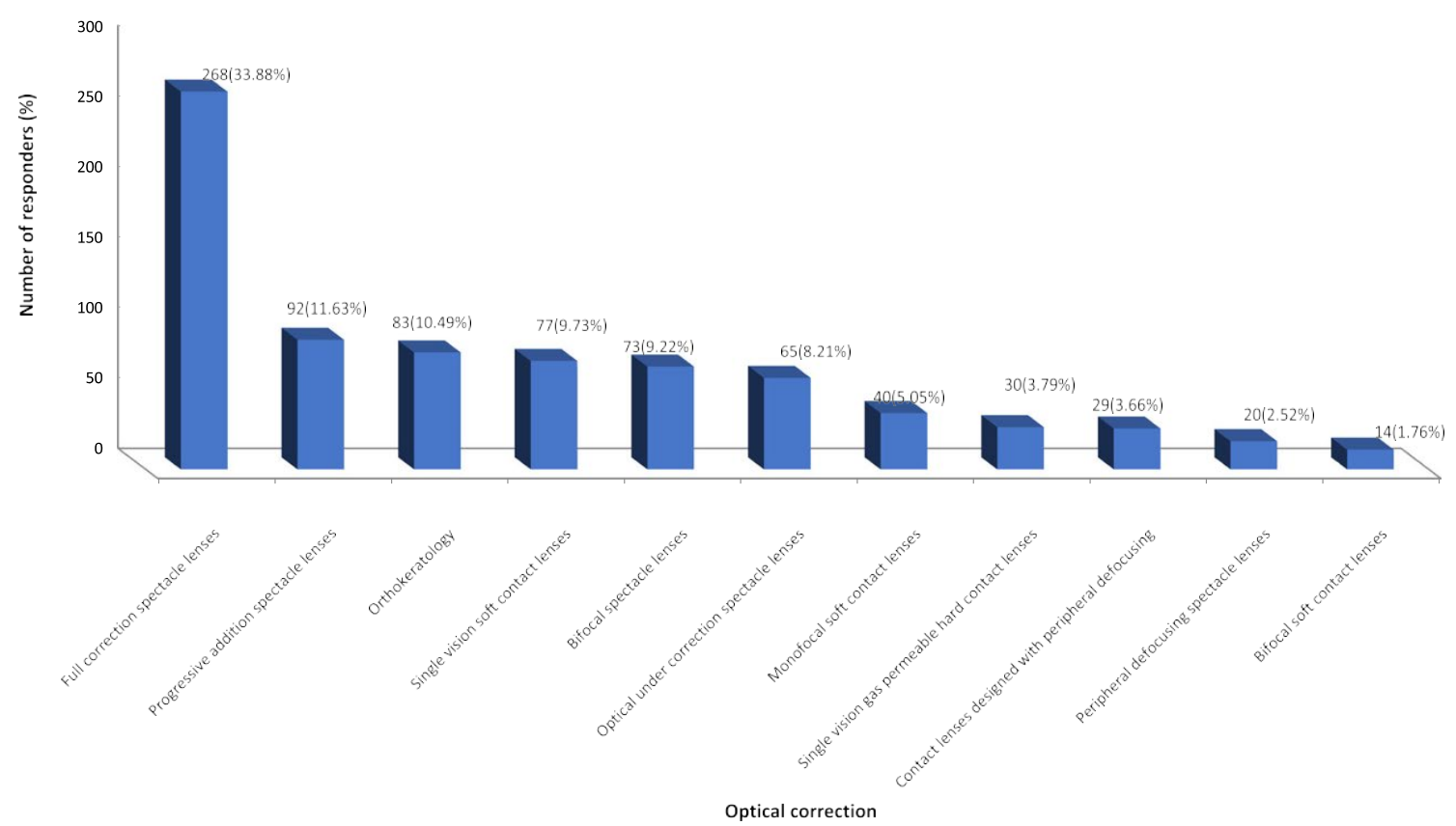

Fig. 3 Type of optical correction used to decrease myopia progression

muscarinic topical medication [29]. During the years, atropine for decreasing progression of myopia was utilized in different dosages $(1,0.5$, $0.3,0.1$, and $0.01 \%$ ). Higher dosages had a stronger initial effect but caused more side effects such as light sensitivity and accommodative insufficiency and furthermore caused a rebound effect [12]. Atropine $0.01 \%$ was found to have the same efficacy after 5 years with few side effects without a rebound effect after cessation $[12,26]$.

Due perhaps to these publications, $70 \%$ of the respondents who choose to utilize pharmacological treatment chose atropine $0.01 \%$. In this survey, atropine $0.01 \%$ was the pharmacological treatment with the highest number of respondents that have not discontinued treatment probably because of its low side effects.
Tong et al. [30] and Chia et al. [31] reported about rebound effect after treatment cessation of atropine. They found a direct correlation between the dosage of atropine and the progression of myopia after discontinuation of this treatment. This was also the trend in this survey.

In this survey, only $16.64 \%$ were of Far East Asia decent, sharing the same ethnic background as the subjects treated in the ATOM studies [12]. Further studies of subjects from other ethnic groups are needed to verify the applicability of these studies to other parts in the world.

Huang et al. performed a network meta-analysis of interventions proposed to reduce myopia progression. Progressive addition spectacle lenses were effective in reducing progression of the refraction. Orthokeratology, peripheral defocus modifying 


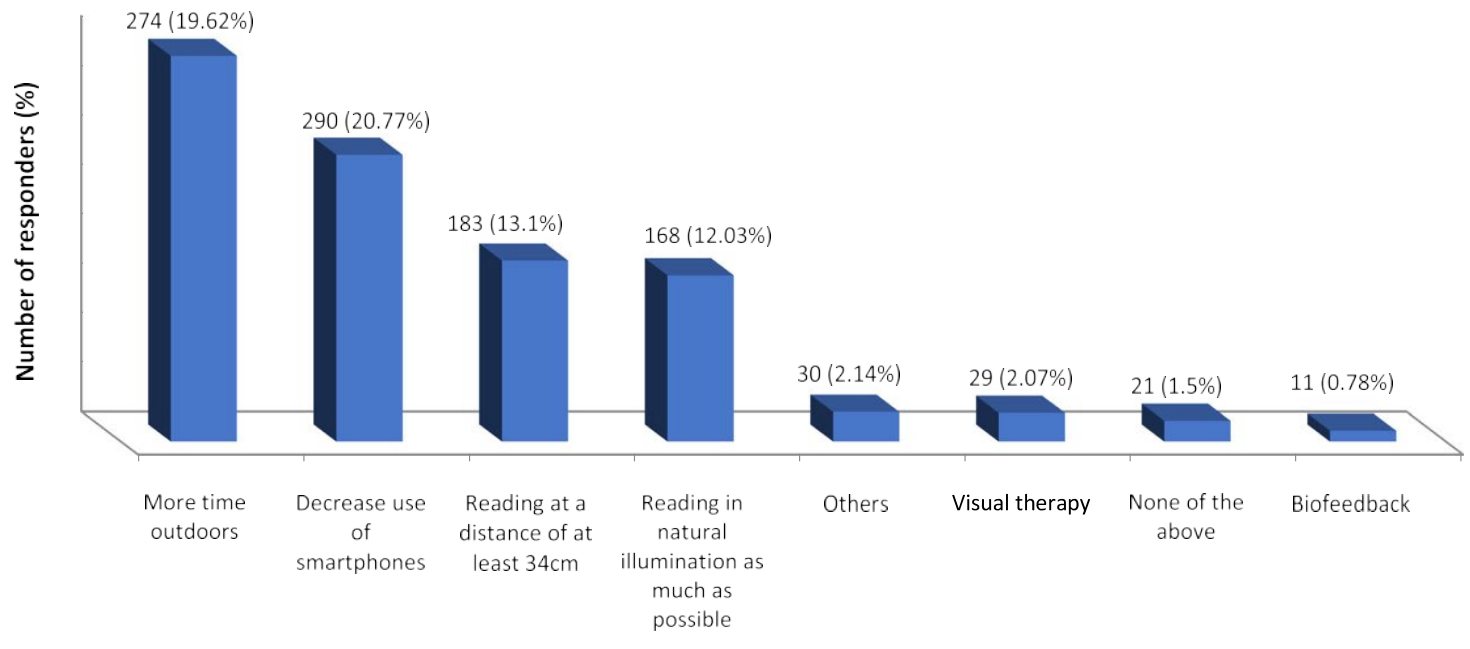

Behavioral recommendation

Fig. 4 Behavior modifications recommended to decrease myopia progression 
contact lenses, and progressive addition spectacle lenses (PAL) were effective in reducing progression of axial length [13]. In contrast, only about a quarter of the respondents who chose optical correction for their patients suggested the use of any one of the types proven to be significantly effective. This may be due to multiple reasons: the moderate effect of some of these modalities (PAL), the high cost of multifocal spectacles and special contact lenses [32], and the increased risk of severe corneal infections in children utilizing overnight contact lenses

[33] as well the low availability of commercially approved contact lenses with peripheral defocusing [34].

Close to $70 \%$ of pediatric ophthalmologists who recommended to modify behavior to decrease myopia progression choose to recommend more outdoor activity and less time using monitors and reading from small screens at near in order to prevent progression of myopia [4, 35]. This is supported by studies that showed the benefit of these changes in type of activity [36]. The most popular behavioral recommendation in this survey was to spend more time outdoors which was proven also as reducing the incidence of myopia in different populations [5, 37]. In addition, it has been reported that behavioral interventions such as decreasing the duration of near work are of benefit [38, 39].

The replies to the questionnaire of Wolffsohn et al. were in contrast to the responses to THE current survey. In their questionnaire, the respondents rated orthokeratology as the most effective method of myopia control, followed by increased time outdoors and pharmaceutical approaches. This may be due to the fact that most of the respondents to this questionnaire were optometrists (72.4\%) and only $18 \%$ were ophthalmologists. Thus, it stands to reason that they advocated optical correction and advocated much less the utility of pharmaceutical approaches as well as behavior modification [32]. In an- other survey that was conducted among members of the Korean Ophthalmological Society, regarding popular treatment options to decrease myopia progression in children, the majority did not support prescribing orthokeratology. Topical atropine was not considered effective. Most practitioners chose to prescribe glasses with full cycloplegic correction [40]. The Korean survey did not deal with many treatment options, but similarly to the current survey, it shows that most respondents prescribed full-correction lenses and not progressive addition lenses that are known to moderately retard the rate of progression of myopia [8]. The study was published in 2011 before treatment with atropine $0.01 \%$ became popular- ized with less rebound and less side effects than treatment with atropine in a higher concentration [41].

There are several limitations to our study: First of all, this was a survey of only pediatric ophthalmologists. Therefore, it may not reflect the clinical practice of other ophthalmologists who treat pediatric myopia. Secondly, there was an unequal representation of ophthalmologists from different parts of the globe and various ethnic 
backgrounds. The views from such countries especially from China are underrepresented in this study. However, this study is the first to include a high number of inter- national centers in a single study, not just sampling a certain continent or ethnic group.

In conclusion, we hope that as time goes by, more pediatric ophthalmologists will join the worldwide effort to decrease the progression of myopia utilizing evidence-based treatment modalities. Nevertheless, not everyone is an early adopter of treatment modalities, $40 \%$ still do not treat at all, and some choose treatments that have not been shown to be significantly effective. One hopes to see more pediatric ophthalmologist treat to decrease the progression of myopia among their pa- tients as additional studies guide us what is the best timing to initiate various types of treatment as well as the applicability of the treatment of atropine $0.01 \%$ in Far East Asians to other ethnic groups. The most popular treatment modalities in this study were topical application of atropine $0.01 \%$ eye drops, full optical correction with spectacles, and encouragement of patients to spend less time in front of monitors and television screens as well as smartphones and tablets and increase time spent outdoors. As more eye care professionals in general and pediatric ophthalmologists in particular start to treat to decrease myopia progression, these endeavors would hopefully help moderate the global epidemic of myopia.

Acknowledgments: We would like to thank all pediatric ophthalmologists who have facilitated the survey to their respective peers in their geographical region or country.

Compliance with ethical standards

Conflict of interest: The authors declare that they have no competing interests.

Ethical approval: This article does not contain any studies with human participants or animals performed by any of the authors.

Informed consent For this type of study, formal consent is not required.

\section{References}

1. Guo K, Yang DY, Wang Y, Yang XR, Jing XX, Guo YY, Zhu D, You QS, Tao Y, Jonas JB (2015) Prevalence of myopia in schoolchildren in Ejina: the Gobi Desert Children Eye Study. Invest Ophthalmol Vis Sci 56(3):1769-1774. https://doi.org/10. 1167/iovs. 14-15737

2. Wu JF, Bi HS, Wang SM, Hu YY, Wu H, Sun W, Lu TL, Wang XR, Jonas JB (2013) Refractive error, visual acuity and causes of vision loss in children in Shandong, China. The Shandong Children Eye Study. PLoS One 8(12):e82763. https://doi.org/10.1371/journal. pone.0082763

3. You QS, Wu LJ, Duan JL, Luo YX, Liu LJ, Li X, Gao Q, Wang W, Xu L, Jonas JB, Guo XH (2014) Prevalence of myopia in school children in greater Beijing: the Beijing Childhood Eye Study. Acta Ophthalmol 92(5):e398-e406 
4. Terasaki H, Yamashita T, Yoshihara N, Kii Y, Sakamoto T (2017) Association of lifestyle and body structure to ocular axial length in Japanese elementary school children. BMC Ophthalmol 17(1):123. https://doi.org/10.1186/s12886-017-0519-y

5. Saxena R, Vashist P, Tandon R, Pandey RM, Bhardawaj A, Gupta V, Menon V (2017) Incidence and progression of myopia and associated factors in urban school children in Delhi: the North India Myopia Study (NIM Study). PLoS One 12(12):e0189774. https:// doi.org/10.1371/journal.pone.0189774

6. Vitale S, Sperduto RD, Ferris FL 3rd (2009) Increased prevalence of myopia in the United States between 1971-1972 and 1999-2004. Arch Ophthalmol 127(12):1632-1639. https://doi.org/10.1001/ archophthalmol.2009.303

7. Matamoros E, Ingrand P, Pelen F, Bentaleb Y, Weber M, Korobelnik JF, Souied E, Leveziel N (2015) Prevalence of myopia in France: a cross-sectional analysis. Medicine 94(45):e1976.

https://doi.org/10.1097/MD.00000000000019 76

8. Holden BA, Fricke TR, Wilson DA, Jong M, Naidoo KS, Sankaridurg P, Wong TY, Naduvilath TJ, Resnikoff S (2016) Global prevalence of myopia and high myopia and temporal trends from 2000 through 2050. Ophthalmology 123(5):1036-1042. https://doi.org/10.1016/j.ophtha.2016.01.006

9. Leo SW, Young TL (2011) An evidence-based update on myopia and interventions to retard its progression. J AAPOS 15(2):181- 189. https://doi.org/10.1016/j.jaapos.2010.09.020

10. Keeffe JE, Chou SL, Lamoureux EL (2009) The cost of care for people with impaired vision in Australia. Arch Ophthalmol 127(10):1377-1381.

https://doi.org/10.1001/archophthalmol.2009. 242

11. Frick KD, Gower EW, Kempen JH, Wolff JL (2007) Economic impact of visual impairment and blindness in the United States. Arch Ophthalmol

125(4):544-550. https://doi.org/10.1001/ archopht.125.4.544

12. Pineles SL, Kraker RT, VanderVeen DK, Hutchinson AK, Galvin JA, Wilson LB, Lambert SR (2017) Atropine for the prevention of myopia progression in children: a report by the American Academy of Ophthalmology. Ophthalmology 124(12):1857-1866. https:// doi.org/10.1016/j.ophtha.2017.05.032

13. Huang J, Wen D, Wang Q, McAlinden C, Flitcroft I, Chen H, Saw SM, Chen H, Bao F, Zhao Y, Hu L, Li X, Gao R, Lu W, Du Y, Jinag Z, Yu A, Lian H, Jiang Q, Yu Y, Qu J (2016) Efficacy comparison of 16 interventions for myopia control in children: a network metaanalysis. Ophthalmology 123(4):697-708. https://doi.org/10.1016/ j.ophtha.2015.11.010

14. Guo Y, Liu LJ, Tang P, Lv YY, Feng Y, Xu L, Jonas JB (2017) Outdoor activity and myopia progression in 4-year follow-up of Chinese primary school children: the Beijing Children Eye Study. PLoS One 12(4):e0175921. https://doi.org/10.1371/journal.pone. 0175921

15. Walline JJ (2016) Myopia control: a review. Eye Contact Lens 42(1):3-8. https://doi.org/10.1097/ICL.000000000000020 7

16. Chuang AY (2017) How to effectively manage myopia. Taiwan J Ophthalmol 7(1):44-47. https://doi.org/10.4103/tjo.tjo_24_17

17. Li SM, Wu SS, Kang MT, Liu Y, Jia SM, Li SY, Zhan SY, Liu LR, Li H, Chen W, Yang Z, Sun YY, Wang N, Millodot M (2014) Atropine slows myopia progression more in Asian than white chil- dren by meta-analysis. Optom Vis Sci 91(3):342-350. https://doi. org/10.1097/OPX.0000000000000178

18. Tay MT, Au Eong KG, Ng CY, Lim MK (1992) Myopia and edu- cational attainment in 421,116 young Singaporean males. Ann Acad Med Singap 21(6):785-791

19. Rong SS, Chen LJ, Pang CP (2016) Myopia genetics - the Asia- Pacific perspective. Asia Pac J Ophthalmol 5(4):236-244. https:// doi.org/10.1097/APO.0000000000000224

20. Mwangi N, Zondervan M, Bascaran C (2017) Analysis of an inter- national collaboration for capacity building of human resources for 
eye care: case study of the college-college VISION 2020 LINK. Hum Resour Health 15(1):22. https://doi.org/10.1186/s12960017- 0196-1

21. Kowal L (2003) Pediatric ophthalmology in Australia. J AAPOS 7(5):311-313. https://doi.org/10.1016/S1091853103001848

22. Padhye AS, Khandekar R, Dharmadhikari S, Dole K, Gogate P, Deshpande M (2009) Prevalence of uncorrected refractive error and other eye problems among urban and rural school children. Middle East Afr J Ophthalmol 16(2):69-74. https://doi.org/10. 4103/0974-9233.53864

23. Li SM, Liu LR, Li SY, Ji YZ, Fu J, Wang Y, Li H, Zhu BD, Yang Z, Li L, Chen W, Kang MT, Zhang FJ, Zhan SY, Wang NL, Mitchell P, Anyang Childhood Eye Study G (2013) Design, methodology and baseline data of a school-based cohort study in Central China: the Anyang Childhood Eye Study. Ophthalmic Epidemiol 20(6):348- 359. https://doi.org/10.3109/09286586.2013.8425 96

24. Williams KM, Bertelsen G, Cumberland P, Wolfram C, Verhoeven VJ, Anastasopoulos E, Buitendijk GH, Cougnard-Gregoire A, Creuzot-Garcher C, Erke MG, Hogg R, Hohn R, Hysi P, Khawaja AP, Korobelnik JF, Ried J, Vingerling JR, Bron A, Dartigues JF, Fletcher A, Hofman A, Kuijpers RW, Luben RN, Oxele K, Topouzis F, von Hanno T, Mirshahi A, Foster PJ, van Duijn CM, Pfeiffer N, Delcourt C, Klaver CC, Rahi J, Hammond CJ, European Eye Epidemiology C (2015) Increasing prevalence of myopia in Europe and the impact of education. Ophthalmology 122(7): 1489-1497. https://doi.org/10.1016/j.ophtha.2015.03.018

25. Polling JR, Kok RG, Tideman JW, Meskat B, Klaver CC (2016) Effectiveness study of atropine for progressive myopia in Europeans. Eye 30(7):998-1004. https://doi.org/10.1038/eye.2016.78

26. Chia A, Lu QS, Tan D (2016) Five-year clinical trial on atropine for the treatment of myopia 2: myopia control with atropine $0.01 \%$ eyedrops. Ophthalmology 123(2):391-399. https://doi.org/10. 1016/j.ophtha.2015.07.004

27. Chia A, Chua WH, Cheung YB, Wong WL,
Lingham A, Fong A, Tan D (2012) Atropine for the treatment of childhood myopia: safety and efficacy of $0.5 \%, 0.1 \%$, and $0.01 \%$ doses (atropine for the treatment of myopia 2). Ophthalmology

119(2):347-354. https://doi.org/10.1016/j.ophtha.2011.07.031

28. Wang YR, Bian HL, Wang Q (2017) Atropine $0.5 \%$ eyedrops for the treatment of children with low myopia: a randomized controlled trial. Medicine 96(27):e7371. https://doi.org/10.1097/MD. 0000000000007371

29. Walline JJ, Lindsley K, Vedula SS, Cotter SA, Mutti DO, Twelker JD (2011) Interventions to slow progression of myopia in children. Cochrane Database Syst Rev 12:CD004916. https://doi.org/10.

1002/14651858.CD004916.pub3

30. Tong L, Huang XL, Koh AL, Zhang X, Tan DT, Chua WH (2009) Atropine for the treatment of childhood myopia: effect on myopia progression after cessation of atropine. Ophthalmology 116(3): 572-579. https://doi.org/10.1016/j.ophtha.2008.10.020

31. Chia A, Chua WH, Wen L, Fong A, Goon YY, Tan D (2014) Atropine for the treatment of childhood myopia: changes after stop- ping atropine $0.01 \%, 0.1 \%$ and $0.5 \%$. Am J Ophthalmol 157(2): 451-457 e451. https://doi.org/10.1016/j.ajo.2013.09.020

32. Wolffsohn JS, Calossi A, Cho P, Gifford K, Jones L, Li M, Lipener C, Logan NS, Malet F, Matos S, Meijome JM, Nichols JJ, Orr JB, Santodomingo-Rubido J, Schaefer T, Thite N, van der Worp E, Zvirgzdina M (2016) Global trends in myopia management atti- tudes and strategies in clinical practice. Cont Lens Anterior Eye 39(2):106-116. https://doi.org/10.1016/j.clae.2016.02.005

33. Spindel GP, Perry HD (1986) Serious corneal complications asso- ciated with extended-wear soft contact lenses for myopia. Ann Ophthalmol 18(4):141-143

34. Smith MJ, Walline JJ (2015) Controlling myopia progression in children and adolescents. Adolesc Health Med Ther 6:133140. https://doi.org/10.2147/AHMT.S55834 
35. Tideman JW, Polling JR, van der Schans A, Verhoeven VJ, Klaver CC (2016) Myopia, a growing health problem. Ned Tijdschr Geneeskd 160:D803

36. Pediatrics AAo (2016) American Academy of Pediatrics announces new recommendations for children's media use. https://www. aaporg/en-us/about-the-aap/aap-pressroom/pages/american- academy-of-pediatricsannounces-new-recommendations-forchildrens-media-useaspx. Accessed 1 May 2018

37. Li SM, Li H, Li SY, Liu LR, Kang MT, Wang YP, Zhang F, Zhan SY, Gopinath B, Mitchell P, Wang N, Anyang Childhood Eye Study G (2015) Time outdoors and myopia progression over 2 years in Chinese children: the Anyang Childhood Eye Study. Invest Ophthalmol Vis Sci 56(8):4734-4740. https://doi.org/10.1167/ iovs.14-15474

38. Wu PC, Chen CT, Lin KK, Sun CC, Kuo CN, Huang HM, Poon YC, Yang ML, Chen CY, Huang JC, Wu PC, Yang IH, Yu HJ, Fang PC, Tsai CL, Chiou ST, Yang YH (2018) Myopia prevention and outdoor light intensity in a school-based cluster randomized trial. Ophthalmology. https://doi.org/10.1016/j.ophtha.2017.12.011

39. Li SM, Kang MT, Peng XX, Li SY, Wang Y, Li L, Yu J, Qiu LX, Sun YY, Liu LR, Li H, Sun X, Millodot M, Wang N (2015) Efficacy of Chinese eye exercises on reducing accommodative lag in school- aged children: a randomized controlled trial. PLoS One 10(3): e0117552.

https://doi.org/10.1371/journal.pone.0117552

40. Jung JJ, Lim EH, Baek SH, Kim YR, Gong SM, Kim US (2011) Attempts to reduce the progression of myopia and spectacle prescriptions during childhood: a survey of eye specialists. Korean J Ophthalmol 25(6):417420.https://doi.org/10.3341/kjo.2011.25.6. 417

41. Chia A, Li W, Tan D, Luu CD (2013) Full-field electroretinogram findings in children in the atropine treatment for myopia (ATOM2) study. Documenta ophthalmologica Advances in ophthalmology 126(3):177-186. https://doi.org/10.1007/s10633-012-9372-8 